\title{
AGÊNCIA E ESTRUTURA: REPRESENTAÇÕES SOCIAIS DA AGRICULTURA NO CAMPO ACADÊMICO
}

Cleber José Bosetti ${ }^{1}$

\begin{abstract}
RESUMO
O objetivo deste artigo foi compreender como ocorre o processo de identificação dos estudantes de agronomia com os modelos de agricultura, a partir da tipificação agricultura produtivista e agroecologia. A metodologia do trabalho envolveu a aplicação de um questionário estruturado em universidades públicas e privadas/comunitárias no Estado de Santa Catarina e a análise de documentos que refletem as concepções curriculares das instituições em relação aos modelos de agricultura. Na primeira aplicamos a análise estatística por associação de variáveis com a utilização do software ' $R$ '; na segunda fizemos a análise de conteúdo dos documentos. Com isso, identificamos que a representação dos modelos de agricultura por parte dos estudantes de agronomia é resultado de uma construção que envolve o habitus trazido pelos estudantes em suas trajetórias sociais e a configuração do campo acadêmico.
\end{abstract}

Palavras-chave: campo acadêmico, habitus, agronomia, agricultura.

\section{AGENCY AND STRUCTURE: SOCIAL REPRESENTATIONS IN THE ACADEMIC FIELD}

\begin{abstract}
The objective of this article was to understand how occurs the process of identifying the students of agronomy with the models of agriculture, from the typification of productivist agriculture and agroecology. The methodology of the work involved the application of a questionnaire structured in public and private/ community universities in the State of Santa Catarina and the analysis of documents that reflect the curricular conceptions of the institutions in relation to the models of agriculture. In the first we applied the statistical analysis by association of variables with the use of software 'R'; in the second we performed the content analysis of the documents. With this, we identify that the representation of agricultural models by students of agronomy is the result of a construction that involves the habitus brought by the students in their social trajectories and the configuration of the academic field.
\end{abstract}

Key words: academic field, habitus, agronomy, agriculture.

\footnotetext{
1 Licenciatura em História (CPEADC). Licenciatura em Filosofia (UNINTER). Especialista em História: Cidade, Cultura e Poder (UNOCHAPECÓ). Especialista em Sociologia (UPF). Mestrado em História Regional (UPF); Doutorado em Sociologia Política (UFSC); Professor Adjunto da Universidade Federal de Santa Catarina (UFSC), campus de Curitibanos. E-mail: cbbosetti@yahoo.com.br
} 


\section{INTRODUÇÃO}

O agro é tech, o agro é pop, o agro é tudo! O fundamento da estrutura dessa representação social é uma mobilização agenciada para estimar o papel econômico da agricultura na atualidade. Com uma pulverização mecânica de imagens que homogeniza as particularidades e oculta as adversidades, o terreno do rural é semeado com a plataforma romântica da eficiência produtiva. Nesta narrativa, são colhidas ideias e imagens que fortalecem o produtivismo, no âmbito do simbólico, a fim de mobilizar as representações sociais através da obscuridade hodierna com que tal marketing é repetido.

Por sua vez, em outros canais de percepção da realidade, há terrenos ditos alternativos sendo cultivados. O lançar das sementes, na direção de um horizonte coberto por incertezas e adversidades, faz emergir outra perspectiva de se construir o rural. Brota assim o campo da agroecologia que, apesar das sucessivas safras já plantadas e colhidas, ainda ocupa um espaço underground no imaginário social que envolve o mundo rural.

Em ambos casos, há um ponto de convergência em que as representações sociais se cruzam e interligam a composição agência/estrutura: o campo acadêmico da ciência agronômica. Isso porque este é um dos campos em que são objetivadas parte das diretrizes que ajudam a construir as dinâmicas da ruralidade. Dessa forma, a compreensão das representações sociais construídas no campo acadêmico ajuda a entendermos os fenômenos sociais que envolvem a agricultura e o mundo rural.

Assim, o objetivo desse artigo é explicar como ocorre a construção da representação social do rural nos estudantes dos cursos de Agronomia a partir do referencial típico ideal de dois modelos de agricultura: a agricultura produtivista e a agroecologia. Para realizar esse estudo utilizamos diferentes estratégias metodológicas com a aplicação de um questionário estruturado com os estudantes de agronomia em 07 universidades no Estado de Santa Catarina, a análise estatística por associação de variáveis das respostas obtidas com esse questionário, a comparação da matriz curricular dos cursos das diferentes instituições de ensino e a análise de conteúdo do perfil dos cursos e dos egressos das universidades estudadas. Com isso, buscamos saber as correlações entre a trajetória social dos estudantes, as instituições de ensino em que os e os modelos de agricultura representados na relação entre agência e estrutura.

\section{CAMPO ACADÊMICO: AGÊNCIA, ESTRUTURA E REPRESENTAÇÃO SOCIAL}

Sabemos que a medida em que os agentes sociais passam a fazer parte de um determinado espaço social, esses assumem uma interação com as regras, os valores e os princípios que regulamentam tal espaço. Os resultados podem não ser previsíveis, porém, não o são totalmente imprevisíveis. A força das operações sociais, que transcorrem em função das relações sociais e dos efeitos simbólicos associados, produz um processo constante de reconstrução social das percepções e das projeções dos agentes sociais. A inserção dos estudantes no campo acadêmico é uma expressão desse tipo de operação de (re)construção dos princípios norteadores da ação social.

A primeira questão a ser considerada sobre o campo acadêmico é sua definição. Este é um campo científico, isto é, um universo no qual estão inseridos os agentes e as instituições que produzem, reproduzem e difundem ações e práticas de um mundo social específico que contém suas próprias regras (BOURDIEU, 1997, p.20-21). O campo acadêmico distingue-se dos demais por ser um espaço fundamentalmente orientado pela racionalidade científica, ou seja, os princípios 
norteadores das ações e relações sociais são, tipicamente, movidos pelo que se pode chamar de espírito científico.

Porém, essa dimensão por si não é suficiente para explicar as ações e representações sociais que são construídas dentro desse espaço. Isso porque os campos da vida social se entrelaçam em uma costura complexa de interações responsáveis pela constituição da visão de mundo dos sujeitos. No caso do campo acadêmico, precisamos considerar a indissociabilidade entre ciência e política, pois as divisões entre os campos do conhecimento, atribuídas à modernidade, são ilusórias (LATOUR, 1994; 2014). Isso significa romper com o imaginário e as práticas de oposição entre estas duas entidades consagradas no imaginário social, afinal, tal oposição foi uma construção histórica que não corresponde à realidade vivida.

Ao inserirem-se no campo científico e estarem sujeitos às regras típicas deste campo, os agentes sociais estão tanto suscetíveis às suas disposições como, a partir de seus habitus, produzem ações ajustadas à posição ocupada (BOURDIEU, 2004, p. 23-25). Antes de entrar em determinado campo, os agentes sociais já carregam consigo determinados habitus que podem ser traduzidos como os saberes, os valores e as visões de mundo que trazem como herança de suas experiências anteriores. Estes elementos funcionam como predisposições que serão reproduzidas ou transformadas, conforme às interações criadas no novo espaço em que estão adentrando.

$\mathrm{Na}$ medida em que passam a fazer parte do campo científico, os agentes sociais aderem a uma estrutura a qual podem responder através da reflexividade (GIDDENS, 1991; 2009), isto é, um reexame das disposições anteriores à luz das novas informações e da necessidade de adequações motivadas pelo contexto em que se encontram. No exercício da reflexividade, os sujeitos elaboram projetos e definem estratégias com base nos recursos que possuem e nas circunstâncias em que estão inseridos (CAETANO, 2011). Entretanto, é preciso lembrar que a relação agência/estrutura também implica na interiorização da exterioridade (BOURDIEU, 2004), isto é, na incorporação das estruturas através do habitus pelos indivíduos. Isso nos leva a considerar a importância da trajetória dos agentes sociais que acessam o campo acadêmico a fim de compreender suas aspirações a partir do confronto entre as disposições trazidas em suas trajetórias de vida e as adquiridas no âmbito acadêmico.

Dessa forma, o campo acadêmico também precisa ser compreendido como um espaço de disputas. Por constituir-se como um espaço social, está permeado por aproximações e distanciamentos, pelo dimensionamento da quantidade de capital, por compatibilidades e incompatibilidades que podem reforçar as afinidades ou promover afastamentos. Isso porque os agentes sociais não são autômatos regulados como relógios segundo leis que lhes escapam, mas investem os princípios incorporados de um habitus gerador (BOURDIEU, 2004). Neste sentido, as experiências construídas e carregadas pelos agentes sociais, bem como suas vinculações e trajetórias, possibilitam aos mesmos atuar com uma relativa margem de manobra diante das instituições, ao mesmo tempo em que estão regidos por suas imposições e expectativas.

É fato que o campo acadêmico é um espaço de disputa por posições que garantem a aquisição do capital simbólico e, por conseguinte, da própria conservação das posições dentro desse ambiente. Assim, configuram-se as relações de autoridade e de dependência que são construídas com base nas posições, disposições e estratégias entre os patrões e clientes, bem como das tensões do mercado e seu ambiente de concorrência (BOURDIEU, 2011). Essas manifestações são perceptíveis, por exemplo, na configuração dos Projetos Pedagógicos Curriculares-PPC, nas Matrizes Curriculares, no delineamento das 
linhas de pesquisa e na vinculação dos estudantes às mesmas, na perspectiva de projeção das carreiras acadêmica e profissional, nos temas de pesquisa com maior representatividade simbólica e investimento financeiro, entre outras. A implicação disso é uma adesão à determinada perspectiva teórica/científica/política, isto é, a uma visão do mundo construída a partir da adesão e da posição ocupada no campo.

No caso das ciências agrárias, uma das disputas correntes no campo acadêmico refere-se aos modelos de agricultura e, por conseguinte, de desenvolvimento rural que lhe são imanentes. Do ponto de vista metodológico, podemos tipificar esses modelos em uma dualidade: a agricultura produtivista e a agroecologia. Estes dois termos são tomados como tipos ideais, isto é, como construções heurísticas utilizadas para analisar a realidade social com o intuito de compreendê-la (WEBER, 1979). Temos consciência de que esta tipificação não abarca o conjunto de teorias e práticas agrícolas possíveis e, por conseguinte, de relações dos agentes sociais para com a realidade do rural. Apenas a consideramos uma forma de divisão teórica que permite uma aproximação da realidade a qual desejamos compreender.

A configuração produtivista da agricultura foi sendo construída de forma concomitante ao desenvolvimento histórico da sociedade capitalista. Na medida em que essa forma social de produção se desenvolveu, especialmente pela divisão do trabalho campo/cidade e pela industrialização, a agricultura adquiriu um sentido de produção eminentemente mercantil (MAZOYER; ROUDART, 2010). No caso da agricultura brasileira, esse processo teve início ainda no período colonial, em que a maior parte da produção agrícola era voltada para a exportação, e foi impulsionado com chamada "modernização conservadora" e a vinculação da agricultura aos complexos agroindustriais a partir da década de 1960 (GRAZIANO SILVA, 1981; MARTINE, 1990).

Recentemente, devido à política econômica do agronegócio, esse processo se ampliou exponencialmente (DELGADO, 2010; 2012; LEITE; WESZ JUNIOR, 2014) e a agricultura brasileira tem se mostrado altamente competitiva e profissionalizante (NAVARRO; PEDROSO, 2011; GASQUEZ; BASTOS; BACCHI, 2011). Com isso, a agricultura produtivista passou a ter forte representatividade simbólica dentro do campo acadêmico constituindo seu mainstream por assim dizer. Essa representação simbólica se expande para imaginário social através de investimentos simbólicos midiáticos que constroem a imagem do agronegócio como a atividade econômica eficiente, sustentável, moderna e que, através dessas representações, oculta uma série de questões arraigadas no processo de produção (SANTOS; OLIVEIRA; GUALBERTO, 2019). Nesse sentido, o rural passa a ter uma representação social que o associa à produtividade, à eficiência e à geração de divisas econômicas como aspectos preponderantes de sua constituição. Apesar disso, as estratégias desenvolvidas por agentes sociais e instituições proporcionam a construção de um rural muito mais complexo e a agroecologia tem despontado como um dos referenciais que dão aporte a tal construção.

A agroecologia pode ser considerada como uma práxis agrícola e social que fornece as diretrizes para um fazer na agricultura que possui fundamentos distintos e baseado em uma pluralidade de saberes (ALTIERI, 1989; GLIESMANN, 2001). A agroecologia possui uma dimensão integral, na qual as variáveis sociais ocupam um papel relevante para a construção de um modelo de agricultura menos dependente em relação à agroindústria e com maior sustentabilidade (GUZMÁN, 2001),bem como por sua capacidade de melhor aproveitar a biomassa disponível no agroecossistema (NETO; MATTOS; CAPORAL, 2018). As proposições da lógica agroecológica emergiram em um contexto de questionamentos do modelo produtivista e suas bases epistemológicas (JACOB, 2016). 
Devido aos impactos ambientais causados pela agricultura moderna convencional, a agroecologia passou a ser concebida como uma forma alternativa de agricultura. Sendo assim, do ponto de vista teórico, considera-se que a agroecologia é uma combinação de ideias ambientais e sociais de uma agricultura preocupada não apenas com a produção, mas com a sustentabilidade social e ambiental do sistema produtivo. No âmbito dessa abordagem, o ser humano, seus modos de vida e o ambiente são elementos centrais na composição do ecossistema.

As perspectivas produtivista e agroecológica são, na atualidade, aspectos constituintes do que podemos denominar de referencial imagético do rural no campo acadêmico. Na medida em que passam a fazer parte desse campo, os agentes sociais estabelecem interações com essas duas dimensões estruturantes. A configuração dessas estruturas e a interação reflexiva que os agentes sociais estabelecem com elas ocorrem, no caso aqui analisado, tanto no passado quanto no presente. No passado podemos dizer que a trajetória social dos estudantes constitui uma dessas estruturas, especialmente sua origem social e o habitus inerente à mesma (BOURDIEU, 1997; 2004); no presente, as estruturas constituintes do campo acadêmico se expressam no PPC, na Matriz Curricular e nas representações dos cursos criadas pelas próprias instituições que, em conjunto, são capazes de influenciar a visão de mundo dos estudantes (DIAS, 2008; SILVEIRA; BALEN, 2004; JACOB; AZEVEDO; SPAROVEK, 2016). Dessa forma, podemos dizer que a representação social dos estudantes é resultante das dinâmicas da interação desses agentes sociais com as referidas estruturas.

Ao analisarmos o perfil demográfico do grupo que compôs a amostragem da presente pesquisa, identificamos tratar-se de uma categoria social: a juventude. Esta categoria é constituída por uma relação complexa entre a idade biológica e a idade social, isto é, entre a atribuição de valor e hierarquização que a segunda impõe a partir e sobre a primeira através de manipulações singulares de cada campo da vida social (BOURDIEU, 1978). Isso significa que a configuração da definição de juventude depende de uma série de variáveis como a profissão, a classe social, as diferentes regiões ou países, etc. Um aspecto interessante de se observar na categoria juventude são as aspirações sociais construídas por este segmento.

Diante de uma sociedade cada vez mais tecnificada e escolarizada, as definições das aspirações e projetos de vida de parcelas significativas da juventude passam pelo campo acadêmico (WHITE, 2015; AMICHI, 2015; BOUZIDI, 2015). No caso da ciência agronômica, os jovens visualizam o rural como possibilidade de vida e trabalho, ou seja, como parte das suas aspirações, projetos de vida e mobilidade social. O conceito de aspiração é usado para analisar o conteúdo quantitativo e qualitativo das metas estabelecidas pelos agentes sociais (SPIELHOFER; GOLDEN; EVANS, 2011). Portanto, entendemos que as disposições do campo acadêmico interferem decisivamente no processo de construção dessas aspirações.

A procura dos estudantes pelo campo acadêmico da ciência agronômica, por si, é uma escolha de acesso ao rural, pois é o resultado de uma ação social deliberada. Resta-nos saber quais são, dentre as possibilidades que gravitam dentro do campo acadêmico, as especificidades desse rural já presente no horizonte das representações sociais dos estudantes. A compreensão da dinâmica do campo acadêmico a partir da tríade que envolve a trajetória social dos agentes e suas disposições adquiridas, o currículo do curso de graduação escolhido e a experiência social de vivenciar o cotidiano do campo acadêmico, são os elementos que nos ajudam a entender as construções e reconstruções das perspectivas acerca do rural por parte dos estudantes de agronomia. 


\section{METODOLOGIA}

Para realizar esse estudo utilizamos diferentes estratégias metodológicas com a aplicação de um questionário estruturado com os estudantes de agronomia em 07 universidades no Estado de Santa Catarina, a análise estatística por associação de variáveis das respostas obtidas com esse questionário, a comparação da matriz curricular dos cursos das diferentes instituições de ensino e a análise de conteúdo do perfil dos cursos e dos egressos das universidades estudadas. Com isso, buscamos saber as correlações entre a trajetória social dos estudantes, as instituições de ensino em que os mesmos estudam e os modelos de agricultura representados na relação entre agência e estrutura.

A metodologia seguiu as seguintes etapas: primeiramente, estabelecemos que a amostragem seria composta pelas universidades catarinenses que possuíssem o curso presencial de agronomia. Após o contato com as instituições, conseguimos a adesão de 7 universidades que compuseram a amostragem da pesquisa, sendo 4 universidades públicas (IPB) e 3 universidades privadas/comunitárias (IPR); em seguida, elencamos o critério de aplicação do questionário. Em função da intenção de captarmos informações do percurso acadêmico e, por se tratar de uma temática de interesse das disciplinas de Sociologia e Extensão Rural, convencionamos a aplicação do questionário nas disciplinas de Extensão Rural das universidades. Pela análise que realizamos dos currículos, essa disciplina é ministrada nas fases finais dos cursos, o que contribuiu para captar as impressões de estudantes com uma carga horária considerável no que tange à trajetória acadêmica.

O questionário foi constituído por questões objetivas e uma questão subjetiva. A compreensão das primeiras foi feita pela análise de tabelas de contingência para duas variáveis. Nisso cruzamos as variáveis (a)Instituição de Ensino (IPB/IPR), (b)trajetória social dos estudantes (filho de agricultor ou não) e (c) sexo com a variável (d)perspectivas de agricultura (agroecologia/agricultura produtivista). Assim, o cruzamento foi o seguinte: $A, B, C$ em relação à $D$. Os resultados dos dados foram submetidos ao Teste de Fisher, o qual possibilita mensurar a probabilidade de significância estatística de uma variável testada (AGRESTTI, 2007). A questão subjetiva presente no questionário foi a seguinte: "O que é o rural para você?" As respostas descritivas dos estudantes foram submetidas à análise Text Mining, isto é, ao processo de obtenção de informações textuais a partir do uso de um programa de contagem de palavras (STAUD JR, 2016). O recurso para fazer tal análise foi o Word Clouds, com o qual destacamos as palavras chave que representam as principais ideias contidas em um texto. Ambas as questões foram analisadas com utilização do Software $R$.

Além do questionário, analisamos os seguintes documentos: Projeto Pedagógico Curricular- PPC- dos cursos e a apresentação dos cursos nas plataformas digitais das universidades. Estes documentos foram analisados com o auxílio do Word Clouds, bem como pelo método qualitativo de análise de discurso. Isso porque os métodos qualitativos ressaltam os efeitos de situação, as interações sociais, o papel do imaginário ou as relações dos atores com as normas sociais (ALAMI, et all, 2010). A natureza da problematização teórica construída pela pesquisa já propunha a utilização da análise qualitativa como estratégia para complementar os resultados obtidos pela investigação quantitativa. Nisso, acrescentamos o instrumento metodológico da análise do discurso, isto é, da correlação entre as condições sociais de produção e reprodução dos discursos proferidos pelos agentes sociais (LECOURT, 2008). 
A análise do discurso, aplicada aos documentos referidos, é uma forma de se apreender as representações do rural inscritas nas instituições de ensino que oferecem os cursos de agronomia. Estes documentos podem ser entendidos como discursos, afinal, são construções históricas situadas em determinado contexto institucional e expressam determinada visão do mundo construídas pelos agentes que ocupam posições representativas dentro do campo acadêmico. A estratégia metodológica, a partir da análise dos discursos, foi feita com a aproximação semântica do conteúdo presente nos documentos analisados em relação ao binômio referência da pesquisa: agricultura produtivista/agroecologia.

\section{RESULTADOS E DISCUSSÃO}

\subsection{AGROECOLOGIA E AGRICULTURA PRODUTIVISTA NA PERCEPÇÃO DOS ESTUDANTES DE AGRONOMIA}

Neste tópico apresentaremos os resultados do questionário, aplicado com os estudantes das Universidades Públicas (IPBs) e Privadas/Comunitárias (IPRs), cuja questão central foi a identificação dos estudantes acerca dos modelos de produção na agricultura: agroecologia e agricultura produtivista.

Uma das questões da pesquisa foi identificar os fatores que motivaram os estudantes a escolherem o curso de graduação em Agronomia. A intenção dessa questão foi visualizar em que medida o binômio agroecologia/agricultura produtivista era um referencial para a escolha do curso. Estas duas variáveis foram colocadas junto às perspectivas de acesso ao mercado de trabalho, de sair de casa ou simplesmente de fazer um curso de graduação porque o mesmo é oferecido próximo ao local de residência.

$\mathrm{Na}$ Tabela 1 identificamos que a agricultura produtivista foi a opção de maior motivação no momento de escolha de curso, tanto nas IPBs quantos nas IPRs. A segunda motivação de maior relevância foi a agroecologia, com $22,97 \%$ nas IPBs e $28,99 \%$ nas IPRs.

Quadro 1 - Porcentagem para opção de escolha de curso por instituição de ensino

\begin{tabular}{|c|c|c|c|c|c|}
\hline \multirow{2}{*}{ Universidade } & \multicolumn{5}{|c|}{ Opção de escolha } \\
\cline { 2 - 6 } & Agroecologia & $\begin{array}{c}\text { Mercado de } \\
\text { trabalho }\end{array}$ & $\begin{array}{c}\text { Agricultura } \\
\text { produtivista }\end{array}$ & $\begin{array}{c}\text { Próximo à } \\
\text { casa }\end{array}$ & Sair de casa \\
\hline IPBs & 22,97 & 18,92 & 37,84 & 8,11 & 12,16 \\
\hline IPRs & 28,99 & 15,94 & 43,48 & 8,70 & 2,90 \\
\hline
\end{tabular}

Fonte: Autor (2019).

No que diz respeito ao binômio referido, podemos notar que tanto nas IPBs quanto nas IPRs a motivação predominante dos estudantes para buscarem o curso de agronomia é mediada pelo referencial da agricultura produtivista. Devido a esse fato, buscamos associar outras variáveis que ajudassem a explicar tal manifestação.

A fim de encontrar variáveis para compreender a motivação inicial dos estudantes em relação à escolha do curso, buscamos contabilizar a distribuição dos estudantes por sexo. Isso porque os cursos de agronomia, tradicionalmente, apresentam uma distribuição bastante desigual no que tange a esse aspecto. 
Quanto à distribuição por sexo nas instituições pesquisadas, obtivemos os seguintes resultados como ilustra a Tabela 2.

Quadro 2- Porcentagem dos estudantes por sexo nas instituições de ensino

\begin{tabular}{|c|c|c|c|}
\hline \multirow{2}{*}{ Universidade } & \multicolumn{3}{|c|}{ Sexo } \\
\cline { 2 - 4 } & Feminino & Masculino & Total \\
\hline IPBs & 22,38 & 29,37 & 51,75 \\
\hline IPRs & 09,09 & 39,16 & 48,25 \\
\hline Total & 31,47 & 68,53 & 100,00 \\
\hline
\end{tabular}

Fonte: Autor (2019).

Podemos visualizar pela Tabela 2 que o predomínio de homens em relação às mulheres ocorre em ambos os grupos de instituições de ensino. Porém, a diferença entre homens e mulheres é ainda mais expressivo nas IPRs enquanto que nas IPBs essa distribuição é mais equilibrada.

Outro aspecto considerado na escolha do curso foi a trajetória social dos estudantes, caracterizada por ser filho de agricultor ou não. Conforme visto anteriormente, o espaço social em que os indivíduos vivem é um espaço formador dos seus habitus, ou seja, dos referenciais de mundo que são utilizados pelos mesmos para orientar suas escolhas. Por isso, conjecturamos a possibilidade de que o fato dos estudantes serem ou não filhos de agricultores, isto é, carregarem em suas trajetórias sociais determinados habitus e expectativas anteriormente construídas, poderia ser uma variável explicativa em relação ao binômio agroecologia/agricultura produtivista.

Notamos pela pesquisa que a variável ser filho de agricultor apresenta porcentagem mais acentuada nas instituições privadas/comunitárias do que nas públicas. Isso pode ser observado na Tabela 3.

Quadro 3 - Porcentagem de filhos de agricultor por grupo de instituição de ensino

\begin{tabular}{|c|c|c|c|}
\hline \multirow{2}{*}{ Universidade } & Sim & Não & Total \\
\cline { 2 - 4 } & & 29,38 & 51,75 \\
\hline IPBs & 34,27 & 13,99 & 48,25 \\
\hline IPRs & 56,64 & 43,36 & 100,00 \\
\hline Total & & & \\
\hline
\end{tabular}

Fonte: Autor (2019)

Uma explicação para essa disposição parece ser a configuração geográfica das instituições, pois as que apresentaram números mais expressivos estão localizadas no Oeste do Estado, região fortemente caracterizada pela presença da agricultura familiar. A análise individualizada em cada instituição de ensino também apontou que, dentre os filhos de agricultores, a maioria das propriedades possuem até 4 Módulos Fiscais, ou seja, apresentam uma característica fundiária que as definem como sendo da agricultura familiar.

O que foi observado nas Tabelas 1, 2 e 3 apresenta um indicativo de que o perfil dos estudantes é caracterizado pelo predomínio de homens em relação às mulheres, pelo número expressivo de filhos de agricultores e por uma maior expectativa de que o curso estivesse voltado para a agricultura produtivista. Em seguida, buscamos verificar se esses aspectos se correlacionam com outra pergunta 
do questionário que dizia o seguinte: "Após realizar parte do percurso formativo, com qual modelo de agricultura você se identifica?" Neste sentido, procuramos correlacionar as variáveis tipo de instituição de ensino, sexo e trajetória social com os modelos de agricultura tipificados, conforme aparece na Tabela 4.

Quadro 4 - Porcentagem do modelo de agricultura por grupo de instituição de ensino

\begin{tabular}{|c|c|c|c|}
\hline \multirow{2}{*}{ Universidade } & Agroecológica & Produtivista & Total \\
\cline { 2 - 4 } & 23,78 & 27,97 & 51,75 \\
\hline IPBs & 04,90 & 43,36 & 48,25 \\
\hline IPRs & 28,67 & 71,33 & 100,00 \\
\hline Total & &
\end{tabular}

Fonte: Autor (2019).

Conforme mostra a Tabela 4, percebemos que as IPBs apresentaram $23,78 \%$ dos entrevistados que se identificam com a agroecologia como modelo de agricultura, enquanto que nas IPRs esse número foi de apenas 04,90\%. Embora em ambas predomine a agricultura produtivista, é possível mensurar que há uma associação estatística significativa entre a variável instituição de ensino com o modelo de agricultura. A verificação foi feita a partir da aplicação do Teste de Fisher para a associação de variáveis, o qual apresentou um valor-p menor que 0,5\%.

Com isso, podemos afirmar que a variável instituição de ensino influencia na maior identificação dos estudantes com a agricultura produtivista e menor identificação com a agroecologia. Isso ocorre especialmente nas IPRs, nas quais o percentual de identificação com a agroecologia como item de opção de escolha de curso era de $28,99 \%$ e, após realizar parte do percurso formativo, foi de $04,90 \%$. Dessa forma, infere-se que a dinâmica do campo acadêmico é um fator que importa no processo de construção das representações sociais do rural nos estudantes de agronomia.

Em contrapartida, ao fazermos a associação entre a variável sexo com os modelos de agricultura identificamos que não há uma significância estatística relevante, pois o Teste de Fisher apresentou um valor-p de 6,39\%. Conforme Tabela 5:

Quadro 5 - Porcentagem de entrevistados por sexo e modelo de agricultura

\begin{tabular}{|c|c|c|c|}
\hline \multirow{2}{*}{ Sexo } & \multicolumn{3}{|c|}{ Modelo de agricultura } \\
\cline { 2 - 4 } & Agroecologia & Agricultura produtivista & Total \\
\hline Feminino & 12,59 & 19,58 & 32,17 \\
\hline Masculino & 16,08 & 51,75 & 67,83 \\
\hline Total & 28,67 & 71,33 & 100,00 \\
\hline
\end{tabular}

Fonte: Autor (2019).

Isso significa que a maior identificação dos estudantes com a agricultura produtivista não é determinada pela variável sexo, tampouco existe uma associação significativa entre o sexo feminino e a agroecologia. Por sua vez, a variável trajetória 
social (filho de agricultor) apresentou uma associação estatística significativa, indicando um valor-p menor de 0,5\%. De acordo com a Tabela 6.

Quadro 6 - Porcentagem de filho de agricultor com o modelo de agricultura

\begin{tabular}{|c|c|c|c|}
\hline \multirow{2}{*}{ Filho de agricultor } & \multicolumn{3}{|c|}{ Modelo de agricultura } \\
\cline { 2 - 4 } & Agroecologia & Agricultura produtivista & Total \\
\hline Não & 18,18 & 25,87 & 44,06 \\
\hline Sim & 10,49 & 45,45 & 55,94 \\
\hline Total & 28,67 & 71,33 & 100,00 \\
\hline
\end{tabular}

Fonte: Autor (2019)

Com isso, podemos afirmar que há uma maior identificação dos estudantes que são filhos de agricultores com o modelo produtivista. Sabemos que o tamanho da amostragem não permite fazer uma inferência genérica, porém, ela indica um caminho para se investigar tal associação. Afim de reforçar essas informações, analisamos uma questão dissertativa que apresentava a seguinte indagação: "O que é o rural para você?" As respostas dissertativas foram analisadas através do Word Clouds do Programa R, conforme a Figura 1.

Figura 1 - Descrição do que é o Rural de acordo com as instituições de ensino

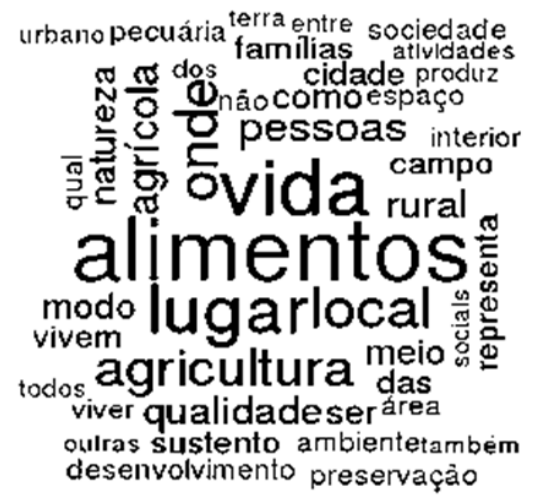

(a) IPBs

Fonte: Autor (2019)

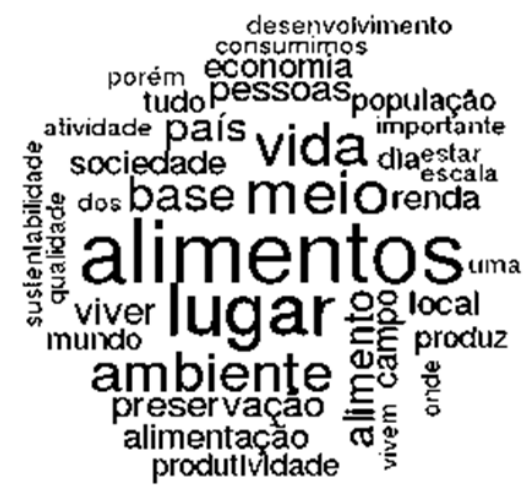

(b) IPRs

Conforme observamos na Figura 1, as descrições sobre o rural nas diferentes instituições são semelhantes. O rural está associado à produção de alimentos, à vida e às pessoas (expressões características da perspectiva agroecológica); e também como espaço da produção de alimentos, base da economia, da agricultura (expressões típicas da agricultura produtivista, que concebe o rural principalmente como atividade econômica).

Como podemos notar o gráfico de nuvens não apontou diferenças significativas entre os tipos de instituição e o imaginário dos estudantes acerca das funcionalidades do rural. Os termos em destaque são 'local da agricultura' e 'produção de alimentos', o que pode contemplar ambos os modelos por seu caráter genérico. O que podemos encontrar são algumas expressões sutis que nos permitem identificar algumas diferenças. Nas IPBs o termo 'vida' aparece em 
destaque e nas IPRs aparecem expressões exclusivas como 'base da economia' e 'produtividade'. Nisso, podemos observar uma pequena diferença de estima em relação à agroecologia nas IPBs e da agricultura produtivista nas IPRs.

\subsection{ESTRUTURA CURRICULAR E O CAMPO ACADÊMICO}

A configuração do campo acadêmico é um fator importante na construção dos referenciais agronômicos dos estudantes. Por isso, elencamos três aspectos do mesmo para analisarmos: a Matriz Curricular e sua respectiva distribuição de disciplinas; o Projeto Pedagógico Curricular e a Apresentação/Divulgação dos cursos nas Plataformas das instituições de ensino.

Uma explicação para compreendermos o motivo pelo qual a identificação com a agroecologia é mais representativa nas universidades públicas (IPBs) parece estar na composição da matriz curricular. A análise da matriz curricular dos cursos nos proporcionou observar que em duas IPRs a disciplina é optativa, enquanto que nas demais instituições esta disciplina é obrigatória. Entendemos que o status da disciplina, optativa ou obrigatória, por si, não assegura a maior ou menor identificação por parte dos estudantes, mas representa um elemento que ajuda a configurar a importância dada à mesma no âmbito das instituições de ensino.

Para ampliar o escopo do estudo, realizamos uma analogia por aproximação semântica das disciplinas ministradas nos cursos, ou seja, a comparação de disciplinas cujos nomes/ementas se aproximam da abordagem agroecológica. Como a agroecologia contempla seu escopo conceitual a combinação entre elementos agronômicos e sociais/humanos, o critério de análise foi a identificação de disciplinas e suas respectivas horas trabalhadas em cada instituição, conforme apresenta a Tabela 7.

Quadro 7 - Disciplinas com abordagem humanística e agroecológica

\begin{tabular}{|c|c|c|}
\hline Universidade & Codificação & Horas \\
\hline \multirow{3}{*}{ IPB } & 1 & 450 \\
\cline { 2 - 3 } & 2 & 288 \\
\cline { 2 - 3 } & 3 & 520 \\
\cline { 2 - 3 } & 4 & 216 \\
\hline \multirow{2}{*}{ IPR } & 1 & 320 \\
\cline { 2 - 3 } & 2 & 160 \\
\cline { 2 - 3 } & 3 & 120 \\
\hline
\end{tabular}

Fonte: Autor (2019)

Destacamos na Tabela 7 o fato de que as três instituições que apresentaram maior carga horária possuem, em suas matrizes curriculares, a disciplina de Estágio de Vivência, na qual os estudantes passam um período junto às famílias dos agricultores para se inteirar da realidade vivida pelos mesmos. A carga horária por si também não assegura a adesão à determinada perspectiva de agricultura. Um caso exemplar disso é a IPR1, em que a carga horária das disciplinas que se interligam com a agroecologia é significativa, porém a identificação dos estudantes com o modelo de agricultura não o é. Em contrapartida, as duas instituições com maior carga horária de disciplinas que contemplam 
aspectos da agroecologia foram as que manifestaram maior identificação dos estudantes para com esta perspectiva de agricultura.

Assim, podemos afirmar que o status da disciplina e o número de horas aula, especialmente quando associados com aspectos do habitus dos estudantes, é um fator relevante na construção das representações sociais do rural. Deste modo, a maior identificação dos estudantes com a agroecologia ou com a agricultura produtivista, estas entendidas como tipos ideais de um universo real mais complexo, depende de um cruzamento de variáveis condicionadas pela combinação entre agência e estrutura.

O segundo aspecto do campo acadêmico que analisamos foi a organização curricular dos cursos, alicerçadas no Projeto Pedagógico Curricular-PPC. Este é um elemento norteador das práticas formativas, pois contém aspectos determinantes e constitutivos da sociedade, da cultura, da ciência, da tecnologia, da economia, da política $e$ das leis que regem $o$ horizonte de determinado campo do conhecimento/profissional (JACOB; ALMEIDA JUNIOR; AZEVEDO; SPAVOREK, 2016).

Em se tratando do curso de Agronomia, até a elaboração das Diretrizes Curriculares Nacionais-DCN em 2006, marco legal que institucionalizou um conjunto mínimo de componentes curriculares tendo em vista a formação de competências e habilidades para um profissional crítico capaz de identificar e resolver problemas, o perfil curricular e institucional dos cursos era, em geral, técnico e alinhado a epistemologia da agricultura empresarial (CAVALLET, 1999; JACOB, 2016). As mudanças trazidas pelas DCNs em 2006 foram um marco legal importante na direção de uma formação plural para as ciências agrárias. A DCN para o curso de agronomia estabelece em seu artigo $5^{\circ}$ os seguintes requisitos para o perfil profissional:

\begin{abstract}
I - sólida formação científica e geral que os possibilite a absorver e desenvolver tecnologia; II - capacidade crítica e criativa na identificação tomada de decisão e resolução de problemas, considerando seus aspectos políticos, econômicos, sociais, ambientais e culturais, com visão ética e humanística, em atendimento às demandas da sociedade; III - compreensão e tradução das necessidades de indivíduos, grupos sociais e comunidade, com relação aos problemas tecnológicos, socioeconômicos, gerenciais e organizativos, bem como utilização racional os recursos disponíveis, além de conservação o equilíbrio do ambiente; e IV - capacidade para adaptação flexível, crítica e criativa às novas situações (BRASIL, 2006).
\end{abstract}

Em linhas gerais, a exigência é de uma sólida formação científica combinada com visão ética e humanista para atender às diversas demandas sociais existentes no espaço rural brasileiro. Neste sentido, a estrutura curricular infere a construção de um projeto pedagógico que contemple a diversidade de demandas. Porém, o currículo é um território de disputas políticas em que as recomendações legais, por vezes, adquirem um aspecto mais formal do que efetivo.

Os currículos transcendem o conjunto de disciplinas ofertadas pelos cursos e são constituídos por escolhas que refletem a materialização de determinadas visões de mundo (DIAS, 2008; JACOB; ALMEIDA JUNIOR; AZEVEDO; APAROVEK, 2016). No caso dos currículos de Agronomia, estes incorporaram um caráter humanístico e interdisciplinar anteriormente ausente (BRASIL, 2006; JACOB, 2016). A obrigatoriedade de uma estrutura curricular mais plural, como foi construída nesse contexto, é um elemento importante para delinear o perfil dos profissionais e da 
própria agricultura. Entretanto, tais diretrizes, por si, não garantem os desdobramentos esperados na medida em que a relação agência/estrutura articulase de modo mais complexo, ou seja, as ações sociais passam por um processo de reflexão e seleção por parte dos agentes sociais em suas relações com as inflexões imanentes às estruturas sociais.

Com o intuito de verificarmos a força mobilizadora da estrutura curricular no campo acadêmico, procuramos analisar os PPCs dos cursos de agronomia nas universidades em que aplicamos a pesquisa. A ideia principal foi de observar, a partir da análise de conteúdo, que tipo de representações sociais acerca do rural predominam nesses documentos. Como nem todas as instituições disponibilizaram o PPC, o que conseguimos fazer foi comparar o "Perfil dos Egressos" e o "Perfil do Curso" disponível nas páginas de divulgação dos cursos de graduação pelas instituições que fizeram parte da amostragem.

O perfil dos egressos é um elemento presente no PPC, portanto, fornece uma informação parcial do mesmo. A apresentação do perfil do egresso pode ser entendida como uma representação da imagem do profissional que se deseja construir. Este aspecto é muito relevante no processo decisório de escolha do curso por parte dos estudantes, afinal, estes carregam juízos e preferências de acordo com seus habitus. Além disso, parece-nos um tipo de documento mais acessado pelos estudantes do que o próprio PPC dos cursos, logo, possui uma capacidade de influenciar nas decisões e no imaginário dos estudantes em relação ao curso.

A seguir, na Figura 2, apresentamos a nuvem de palavras referente ao perfil dos egressos das IPBs e IPRs.

Figura 2 - Perfil dos egressos nas IPRs e IPBs:

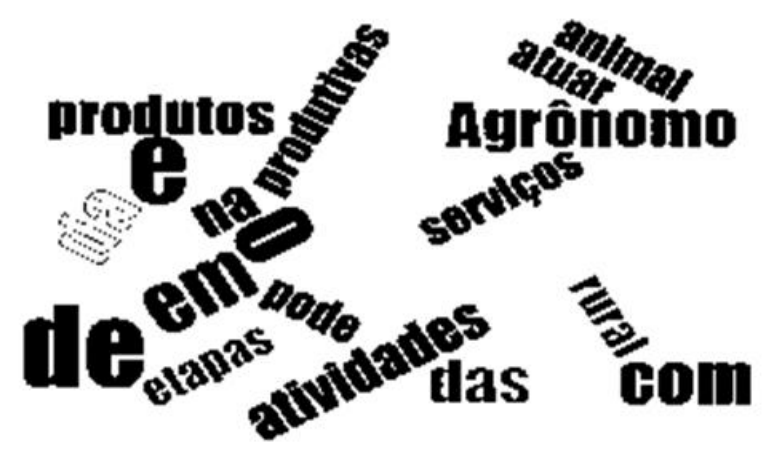

IPRs 


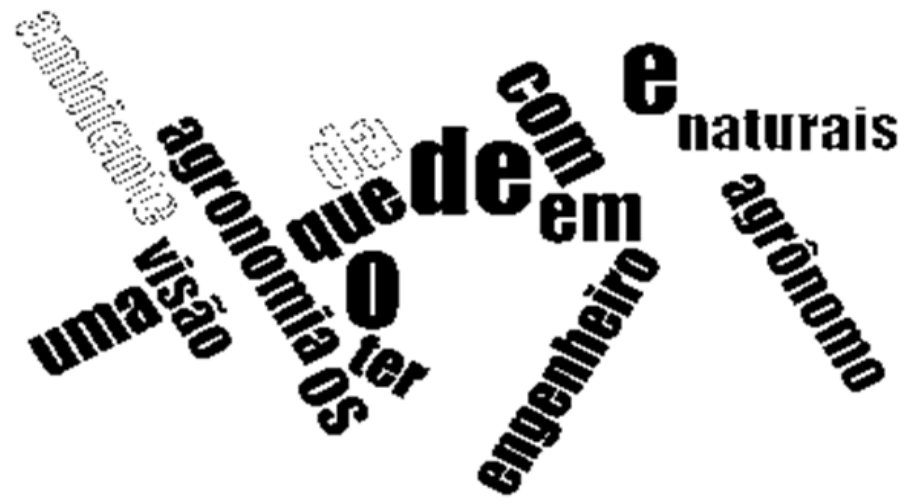

IPBs

Fonte: Autor (2019)

Conforme mostra a Figura 2, nas IPRs predominam expressões como "agrônomo", "produção", "atividades produtivas" e "produtos" e nas IPBs destacamse expressões como "engenheiro agrônomo", "profissional", "ambiente" e "naturais". O que podemos deduzir dessa análise é que, além das palavras que expressam pontos comuns, há no perfil dos egressos das IPBs uma maior aproximação semântica com o referencial da agroecologia em comparação com as IPRs.

A fim de apresentar elementos mais detalhados que consigam expressar as diferenças de concepção em relação à tipificação institucional escolhida, recortamos alguns extratos da apresentação do "Perfil do Curso" de algumas das instituições analisadas.

O extrato a seguir refere-se ao Perfil do Curso em duas IPBs:

"O curso tem como ênfase a agroecologia, ciência com raízes nos métodos e nas práticas tradicionais de manejo produtivo dos ecossistemas pelas populações camponesas, que se baseiam na valorização dos recursos naturais disponíveis em cada localidade. Seus princípios apontam caminhos que evidenciam uma perspectiva clara de construção de uma concepção de sustentabilidade, abrindo as portas para novas opções de práticas sociais, incluindo o manejo da agricultura, pecuária e organização social. O profissional deverá ter sólido conhecimento técnico-científico no campo da agronomia, com ênfase na agroecologia, tendo espírito empreendedor, criativo, apto a avaliar, planejar, manejar e monitorar agroecossistemas, junto com os agricultores e seguindo processos ecológicos (IpB4). O curso de agronomia tem como objetivo formar profissional com sólido conhecimento técnico-científico e responsabilidade social, com capacidade de concepção, a partir de uma visão holística e apto a aplicar princípios e processos ecológicos no desenho e no manejo de agroecossistemas, de forma a torná-los produtivos e ambientalmente sustentáveis (IPB1)." 
Há no perfil do curso dessas instituições não somente significantes que sintonizam a perspectiva formativa em relação às $D C N s$, mas a indicação de uma orientação para a pluralidade de atuação do engenheiro agrônomo. Ao destacar "a ênfase na agroecologia", "o sólido conhecimento científico associado à responsabilidade social" e "a aptidão para planejar, avaliar e manejar os agroecossistemas“, vemos que o perfil dos cursos dessas IPBs atribui um espaço formativo com maior atenção à agroecologia. Isso porque a perspectiva agroecológica compreende a intervenção técnica a partir da harmonização dos fatores que compõe a complexidade do agroecossistema, tendo em vista o equilíbrio ecológico dos fatores de produção (ALTIERI, 2989; LEFF, 2000).

A seguir, extratos do Perfil do Curso em três IPRs:

\begin{abstract}
"O curso de Agronomia tem como objetivo formar profissionais com uma forte e sólida base técnico-científica para atuar em todas as etapas da produção e gestão das cadeias produtivas de alimentos, senviços e matérias-primas, de modo sustentável, para permitir o contínuo avanço socioeconômico da sociedade (IPR3). O curso prepara o profissional para participar das etapas das cadeias produtivas da agricultura. Pode atuar em organizações regionais e nacionais, ocupação do espaço rural, produção animal ou vegetal, transformação, comercialização e serviços e atividades de planejamento rural. Cuida da ligação entre campo e cidade. No desenvolvimento rural, envolve-se na educação, inovação, pesquisa de mercado, tecnológica, produção de insumos e prestação de serviços (IPR1); O formado pode atuar em multinacionais no ramo de insumos, processadoras de produtos finais, cooperativas, instituições de pesquisa, instituições financeiras, seguradoras, indústrias de máquinas e implementos ou administrar seu próprio negócio. $O$ agrônomo também pode trabalhar no desenvolvimento de novos produtos e na otimização de tecnologias produtivas (IPR2)"
\end{abstract}

As expressões "participar das cadeias produtivas", "atuar em organizações multinacionais" são muito significativas na indicação de uma agricultura voltada para o agronegócio em sua dimensão econômica. Importante ressaltar que essa forma de apresentação está em consonância com o imaginário já presente em parte dos estudantes que procuram o curso de agronomia, conforme vimos no questionário analisado anteriormente. Assim, confirma-se a tendência na formação profissional das ciências agrárias de estar voltada para uma agricultura em grande escala, intensiva em mecanização e insumos químicos, em que se perdem as especificidades dos cultivos em relação aos sistemas naturais (SILVEIRA; BALEM, 2004).

Dessa forma, no que se refere ao campo acadêmico, podemos afirmar que existem elementos estruturantes que diferenciam de forma sutil as perspectivas formativas na ciência agronômica entre as IPBs e as IPRs. Seja pela carga horária de disciplinas, pelas expectativas em relação aos egressos e pela apresentação do perfil do curso, notamos que a agroecologia possui um sutil ganho de espaço nas IPBs em relação às IPRs. Assim, ressaltamos o fato de que as instâncias normativas presentes na estrutura do campo acadêmico constituem um aspecto a ser considerado na composição das estruturas definidoras das práticas e representações. Entretanto, o impacto dessa estrutura sobre os estudantes é ativado, principalmente, quando o habitus e as demandas oriundas dos próprios estudantes também atuam como estruturas estruturantes para a constituição da configuração do campo acadêmico. 


\section{CONSIDERAÇÕES FINAIS}

O estudo das representações sociais a partir da dinâmica do campo acadêmico nos mostrou que há um conjunto de variáveis atuantes na construção das perspectivas de agricultura por parte dos estudantes de Agronomia. As diretrizes curriculares nacionais, que normatizam os cursos, são uma variável estruturante que sugere uma formação profissional baseada na pluralidade e diversidade. Entretanto, identificamos que essas diretrizes possuem aplicações enviesadas e distintas nas diferentes instituições de ensino, pois estas utilizam sua capacidade de agência para adequar os cursos às demandas sociais do seu público, bem como refletem as relações de poder que ocorrem no campo acadêmico na medida em que os agentes sociais fazem suas escolhas com base na reflexividade.

As trajetórias sociais dos estudantes, traduzidas aqui a partir do conceito de habitus, ou seja, as práticas e representações construídas pelos agentes sociais, também foi um fator fundamental na configuração das representações sobre os modelos de agricultura. Denominada com a variável filho de agricultor, os agentes sociais com esta trajetória social demonstraram uma maior identificação com o modelo de agricultura produtivista, aspecto que é reforçado quando há uma convergência nesta direção por parte das instituições de ensino. A análise estatística demonstrou que nas universidades privadas/comunitárias os estudantes possuem maior identificação com o modelo produtivista do que nas universidades públicas, especialmente quando a convergência mencionada anteriormente é preponderante. Nas Instituições públicas, a identificação com a agroecologia 'por parte dos estudantes é maior em relação às instituições privadas, o que se deve em parte por aspectos constitutivos dos currículos bem como pela composição das trajetórias sociais e dos habitus embutidos nas mesmas.

Diante de tais manifestações, consideramos que as representações sociais acerca da agricultura, no âmbito do campo acadêmico, ocorrem a partir das relações entre agência e estrutura. Por um lado, o habitus trazido pelos estudantes funciona como uma estrutura estruturante que define não somente opções políticas dos mesmos, mas influencia a própria configuração dos cursos oferecidos pelas instituições de ensino; por sua vez, as instituições fazem ajustamentos nos currículos para adequarem-se, simultaneamente, às Diretrizes Curriculares Nacionais e às motivações trazidas pelos estudantes que constituem o público alvo de suas ofertas formativas. Além disso, podemos observar que a composição da estrutura curricular em suas diversas manifestações, pode ser, ainda que de modo relativo, um elemento delineador de práticas e representações sociais. Na medida em que o campo acadêmico concede maior espaço a determinado modelo de agricultura, o mesmo se reflete nas representações sociais dos estudantes. Portanto, as relações entre agência e estrutura definem as representações sociais em relação à agricultura a partir de um complexo jogo de disposições efetuadas conforme os interesses dos interessados em jogar esse jogo.

\section{REFERÊNCIAS}

AGRESTTI, A. An introduction to categorical data analysis. 2.ed. WileyInterscience A. John Wiley \& Sons, Wiley Series in Probability and Statistics, 2007.

ALTIERI, M. Agroecologia: as bases científicas da agricultura alternativa. Rio de Janeiro: PTA/FASE, 1989. 
$\mathrm{AMICHI}, \mathrm{H}$. et al. Une génération em quête d'opportunités et de reconnaissance: les jeunes ruraux el leurs trajectoires innovantes dans l'agriculture irriguée au Maghreb. Cahier Agricole, vol 24, número 06, novembre-décembre, 2015.

BALSADI, O. V; DEL GROSSI, M. E. Trabalho e emprego na agricultura brasileira: um olhar para o período 2004-2014. Revista de Política Agrícola, Brasília, ano XXV - n, 4, out./dez. 2016.

BARBETTA, P. A. Estatística aplicada às ciências sociais. Florianópolis: UFSC, 2010.

BOURDIEU, P. La jeunesse n'est qu'un mot. Association des ages, Paris, 1978, p.520-530.

BOURDIEU, P. Os usos sociais da ciência: por uma sociologia clínica do campo científico. São Paulo: UNESP, 1997.

BOURDIEU, P. Coisas ditas. São Paulo: Brasiliense, 2004.

BOURDIEU, P. Homo academicus. Florianópolis: UFSC, 2011.

BOUZIDI, Z. et al. Mobiliser des ressources techniques et sociales pour s'installer: strategies des jeunes ruraux au Maroc. Cahier Agricole, v. 24, n. 6, nov./déc. 2015.

CAETANO, A. Para uma análise sociológica da reflexividade individual. Sociologia, problemas e práticas, n. 66, 2011, p. 157-174.

CARNEIRO, M. J; GAUARANÁ DE CASTRO, E (Org). Juventude rural em perspectiva. Rio de Janeiro: Mauad X, 2007.

CORE TEAM R. (2017) Language and environment for statistical computing R. Foundation for Statistical Computating, Vienna, Austria.

DELGADO, G. C. Especialização primária como limite ao desenvolvimento. Desenvolvimento em Debate, v.1, n.2, p.111-125, janeiro-abril e maio-agosto 2010.

DIAS, M. M. A formação do agrônomo como agente de promoção do desenvolvimento. Extensão Rural, Santa Maria, n.15, Ano XV, p.53-68 jan./jun. 2008. Disponível em: https://periodicos.ufsm.br/extensaorural/article/view/9625/5772. Acesso em: 23 set. 2019.

GASQUES, J. G; BASTOS, E. T; BACCHI, M. Produtividade e crescimento da agricultura brasileira. Agronegócios. Instituto Interamericano de Cooperação para a Agricultura - IICA, Brasília, 2011.

GIDDENS, A. As consequências da modernidade. São Paulo: UNESP, 1991.

GIDDENS, A. A constituição da sociedade. São Paulo: Martins Fontes, 2009.

GLIESSMAN, S. Agroecologia: processos ecológicos em agricultura sustentável. Porto Alegre: Ed. Universidade/UFRGS, 2001. 
GRAZIANO SILVA, J. Modernização dolorosa: estrutura agrária, fronteira agrícola e trabalhadores rurais no Brasil. Rio de Janeiro: Zahar, 1981.

GUZMÁN, E. S. Uma estratégia de sustentabilidade a partir da agroecologia. Revista Agroecologia e Desenvolvimento Rural Sustentável, Porto Alegre, v.2, n.1, jan./mar.2001.

JACOB, L. B; ALMEIDA JR, A. R. de; AZEVEDO, M. A. R. de; SPAROVEK, G. A agroecologia nos cursos de engenharia agronômica: para além de desafios e dilemas curriculares. Avaliação, Campinas; Sorocaba, SP, v. 21, n. 1, p. 173-198, mar. 2016.

JACOB, L. B. Agroecologia na universidade: entre vozes e silenciamentos. Curitiba: Appris, 2016.

LATOUR, B. Jamais fomos modernos: ensaio de antropologia simétrica. Rio de Janeiro: Editora 34, 1994.

LATOUR, B. Para distinguir amigos e inimigos no tempo do antropoceno. Revista de Antropologia, São Paulo, v. 57, n.1, p.11-31, 2014.

LEITE, S. P; WESZ JR, V. J. Políticas públicas e agronegócio no Brasil. Revista Pós Ciências Sociais, v.11, n.22, jul./dez. 2014.

MARTINE, G. A trajetória da modernização agrícola: a quem beneficia? Brasília, IPEA, 1990.

MAZOYER, M; ROUDART, L. História das agriculturas no mundo: do neolítico à crise contemporânea. São Paulo: UNESP; Brasília: NEAD, 2010.

NAVARRO, Z; PEDROSO, M. T. M. Agricultura familiar: é preciso mudar para avançar. Brasília: EMBRAPA, 2011.

NETO, J. B. M; MATTOS, J. L. S.; CAPORAL, F. R. Análise da dinâmica energética de agroecossitemas. Extensão Rural, Santa Maria, v.25, n.3, p. 73-88, jul./set. 2018. Disponível em: https://periodicos.ufsm.br/extensaorural/article/view/32691/pdf. Acesso em: 23 set. 2019.

STAUDT JR, J. L. Text mining utilizando o software R: um estudo de caso de uma biblioteca americana. TCC. Porto Alegre: UFRGS, 2016.

SILVEIRA, P. R. C; BALEM, T. A. A formação profissional e extensão rural: incapacidade da superação do modelo agrícola. In: VI ENCONTRO DA SOCIEDADE BRASILEIRA DE SISTEMAS DE PRODUÇÃO, 6., 2004, Aracaju, Anais... Sergipe, 2004.

SANTOS, Z.; OLIVEIRA, U. J.; GUALBERTO, C. L. O discurso midiático do agronegócio no Brasil sob um olhar da análise discursiva crítica e da semiótica Social. Diálogo das Letras, Pau dos Ferros, v. 8, n. 1, p. 159-178, jan./abr. 2019.

SPIELHOOFER, T, GOLDEN, S; EVANS, K. Young people's aspirations in rural areas. Slough (UK): NFER, 2011. 
WEBER, M. Ensaios de sociologia. Rio de Janeiro: Zahar Editores, 1979.

WHITE, B. Generational dynamics in agricultue: refletions on rural youth and farming.

Cahier agricole, v. 24, n. 6, nov./déc. 2015. 